\title{
Crystal Growth of GaN from Na-Ga Melt in BN Containers
}

\author{
Hisanori YAMANE, Dai KINNO, Masahiko SHIMADA and Francis J. DISALVO* \\ Institute for Advanced Materials Processing; Tohoku University, 2-1-1, Katahira, Aoba-ku, Sendai-shi 980-8577 \\ *Department of Chemistry, Cornell University, Ithaca, New York 14853, USA
}

\author{
BN 容器中における $\mathrm{Na}-\mathrm{Ga}$ 融液からの GaN の結晶成長 \\ 山根久典・金野 大・島田昌彦・Francis J. DiSalvo* \\ 東北大学素材工学研究所, 980-8577 仙台市青葉区片平 2-1-1 \\ *Department of Chemistry, Cornell University, Ithaca, New York 14853, USA
}

\begin{abstract}
A melt of $\mathrm{Na}$ and $\mathrm{Ga}$ with various Ga contents was placed in a $\mathrm{BN}$ crucible and reacted at $650^{\circ} \mathrm{C}$ for $300 \mathrm{~h}$ with $\mathrm{N}_{2}$ generated from the decomposition of $\mathrm{NaN}_{3}$ in a sealed stainless-steel tube. At 0.25 and 0.45 Ga molar fractions $\left(r_{\mathrm{Ga}}=\mathrm{Ga} /(\mathrm{Ga}+\mathrm{Na})\right)$, GaN precipitated at the interface of the melt and gas phases, and on the wall and bottom of the crucible. Platelet single crystals with a maximum size of $2 \mathrm{~mm}$ grew at the inside of the interface layer. The precipitates on the wall and bottom consisted of hexagonal columnar crystals elongated along the $c$-axis direction. The size of these crystals was about $10-20 \mu \mathrm{m}$ at $r_{\mathrm{Ga}}=0.25$ and $50-100 \mu \mathrm{m}$ at $r_{\mathrm{Ga}}$ $=0.45$. The morphology of the precipitates observed by scanning electron microscopy suggested that the columnar GaN crystals grew from the melt phase. At $r_{\mathrm{Ga}}=0.65$ and 0.85 , thin GaN microcrystalline layers partially covered the Na-Ga melt surface, but the formation of bulk GaN was not observed in the BN crucible.
\end{abstract}

[Received May 24, 1999; Accepted July 21, 1999]

Key-words : GaN, Single crystal, Crystal growth, Morphology, Na flux, Na-Ga melt

\section{Introduction}

Blue-light-emitting diodes and diode lasers of III-V nitrides based on GaN have been investigated intensively. Many papers note the lack of suitable substrates for $\mathrm{GaN}$ film deposition. ${ }^{1)-3)}$ Needless to say, high-quality GaN thin film could be fabricated homoepitaxially on single-crystal substrates of GaN itself. However, the largest bulk GaN single crystals obtained at present are platelets with a size of about $1 \mathrm{~cm}$ in the longest direction. ${ }^{4)}$ These crystals were grown from a Ga melt at $1300-1700^{\circ} \mathrm{C}$ and $1-2 \mathrm{GPa}$ of $\mathrm{N}_{2}$. GaN single crystals of $\mathrm{mm}$ scale have been prepared from the vapor phase or by a liquid-vapor-solid process at around $1000^{\circ} \mathrm{C}$ in $\mathrm{NH}_{3}$ atmosphere. ${ }^{5)-12)}$ Recently, we have succeeded in preparing GaN single crystals with a maximum size of $2 \mathrm{~mm}$ by heating $\mathrm{Ga}$ and $\mathrm{NaN}_{3}$ sealed in a stainless-steel tube at $650-850^{\circ} \mathrm{C}$ for $24-200$ h. ${ }^{13)-15)} \mathrm{NaN}_{3}$ decomposes into $\mathrm{Na}$ and $\mathrm{N}_{2}$ at around $300^{\circ} \mathrm{C}$. The effect of $\mathrm{Na}$ was investigated by adding extra amounts of $\mathrm{Na}$ in the tube. ${ }^{15)}$ We observed the formation of the crystals in the tube. It was found that the Na-Ga melt wetted the stainlesssteel tube wall well and platelet crystals of $1-2 \mathrm{~mm}$ in size grew perpendicular to the tube wall. Growth of granular and prismatic crystals was also seen. However, we could not conclude whether the area of crystal growth was limited to near the interface of the Na-Ga melt or not. This information is important in designing a method of large-scale single-crystal growth using the $\mathrm{Na}-\mathrm{Ga}$ melt. In the preliminary study, we tested other kinds of metals such as $\mathrm{Ni}, \mathrm{Fe}, \mathrm{Co}, \mathrm{Mo}$ and $\mathrm{Nb}$ for use as crucible materials. All of them were wetted well by the Na-Ga melt, and some of them reacted with the $\mathrm{Na}-\mathrm{Ga}$ melt. In the present work, we used a boron nitride crucible and studied the growth of $\mathrm{GaN}$ single crystals in the Na-Ga melt with various $\mathrm{Ga}$ contents.

\section{Experimental}

The starting materials used were Ga (Sumitomo Chemical Co., Ltd., 99.9999\% purity), Na metal (Koujundo Chemicals Lab. Co., Ltd., 99\% purity) and $\mathrm{NaN}_{3}$ (Toyo Kasei Kogyo Co., Ltd., 99.9\% purity). Ga (2.5-8.5 mmol) and $\mathrm{Na}(7.5-1.5 \mathrm{mmol})$ were weighed at the ratios listed in
Table 1 and placed in a BN crucible ( $7 \mathrm{~mm}$ inner diameter, $15 \mathrm{~mm}$ depth, Showa Denko K. K., 99.5\% purity). As shown in Fig. 1, the crucible was set in a stainless-steel tube (SUS 316, $10.7 \mathrm{~mm}$ inner diameter, $90 \mathrm{~mm}$ in length) with a stainless-steel pole (SUS $316,6.4 \mathrm{~mm}$ in diameter, $30 \mathrm{~mm}$ in length), and sealed with $7.2 \mathrm{mmol} \mathrm{NaN}_{3}$ with stainless-steel caps. This process was carried out in an MBraun MB130 glove box in which the combined $\mathrm{O}_{2}$ and

Table 1. Experimental Conditions and Products

\begin{tabular}{lcccc}
\hline Sample & A & B & C & D \\
\hline $\begin{array}{l}\mathrm{Ga} / \mathrm{Na} \\
(\mathrm{mmol} / \mathrm{mmol}) \\
r_{\mathrm{Ga}}^{*}\end{array}$ & $2.5 / 7.5$ & $4.5 / 5.5$ & $6.5 / 3.5$ & $8.5 / 1.5$ \\
products & 0.25 & 0.45 & 0.65 & 0.85 \\
& $\begin{array}{l}\mathrm{GaN}, \mathrm{Na} \\
\text { 》 Ga-Na }\end{array}$ & $\begin{array}{l}\mathrm{GaN}, \mathrm{Na}, \\
\mathrm{Ga}-\mathrm{Na}\end{array}$ & $\begin{array}{l}\mathrm{Ga}-\mathrm{Na} \\
>\mathrm{GaN}\end{array}$ & $\begin{array}{l}\mathrm{Ga}-\mathrm{Na}, \mathrm{Ga} \\
\gg \mathrm{GaN}\end{array}$ \\
\hline
\end{tabular}

${ }^{*} r_{\mathrm{Ga}}=\mathrm{Ga} /(\mathrm{Ga}+\mathrm{Na})$ mol fraction

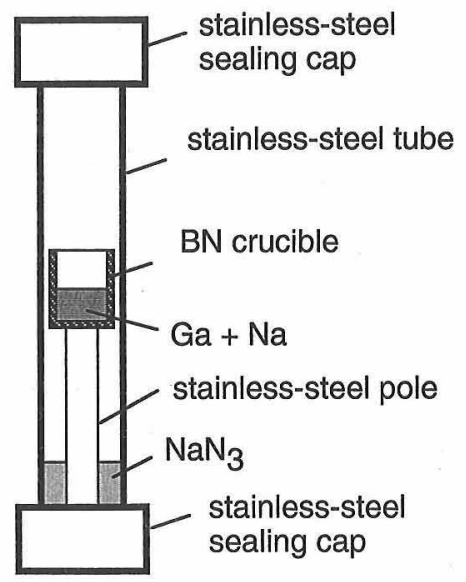

Fig. 1. Schematic view of the reaction container. 
$\mathrm{H}_{2} \mathrm{O}$ content was below $1 \mathrm{ppm}$. The sealed tube was set vertically in a furnace and heated at $650^{\circ} \mathrm{C}$ for $300 \mathrm{~h}$ in air. After heating, the sample in the tube was cooled to room temperature by shutting off the furnace power. The $\mathrm{Na}$ metal was removed by reaction with 2-propanol and ethanol. The products in the tube were observed using an optical microscope and a scanning electron microscope (SEM; Hitachi, Ltd., S2150). Fragments and powders of crystals were characterized by X-ray diffraction (XRD). $\mathrm{Cu} \mathrm{K} \alpha$ radiation was used on a diffractometer with a pyrolitic graphite monochromator (Rigaku, RINT2500).

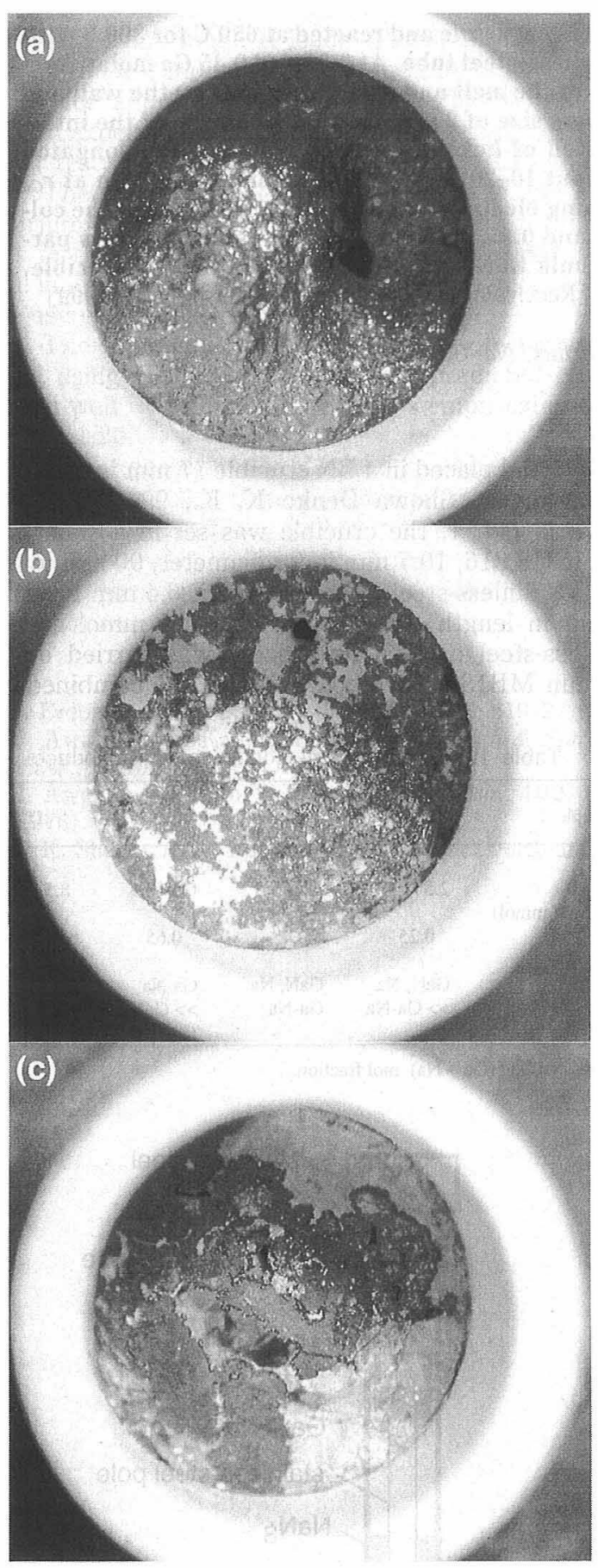

Fig. 2. Photographs of samples A (a), B (b) and C (c) prepared by heating at $650^{\circ} \mathrm{C}$ for $300 \mathrm{~h}$ in $\mathrm{BN}$ crucibles $(7 \mathrm{~mm}$ inner diameter).

\section{Results and discussion}

Figure 2 shows photographs of the samples in the $B N$ crucible. The surfaces of the samples obtained under all conditions (samples A-D) were convex upward and exhibited poor wettability against $B N$.

The surface of sample A was covered with a GaN layer. $\mathrm{Na}$ metal oozed out from the inside to the surface. The inside was filled with $\mathrm{Na}$ metal and contained small amounts of needle crystals with a silver metallic luster. According to the $\mathrm{Na}-\mathrm{Ga}$ binary phase diagram ${ }^{16)}$ and our previous

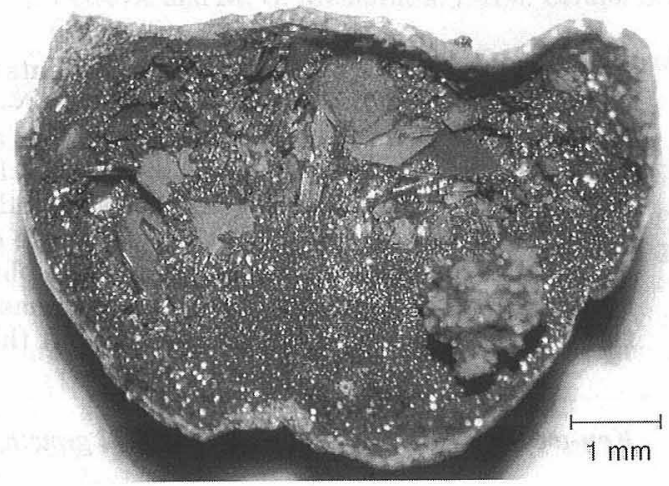

Fig. 3. Photograph of the GaN surface layer of sample A taken from the melt-phase side.
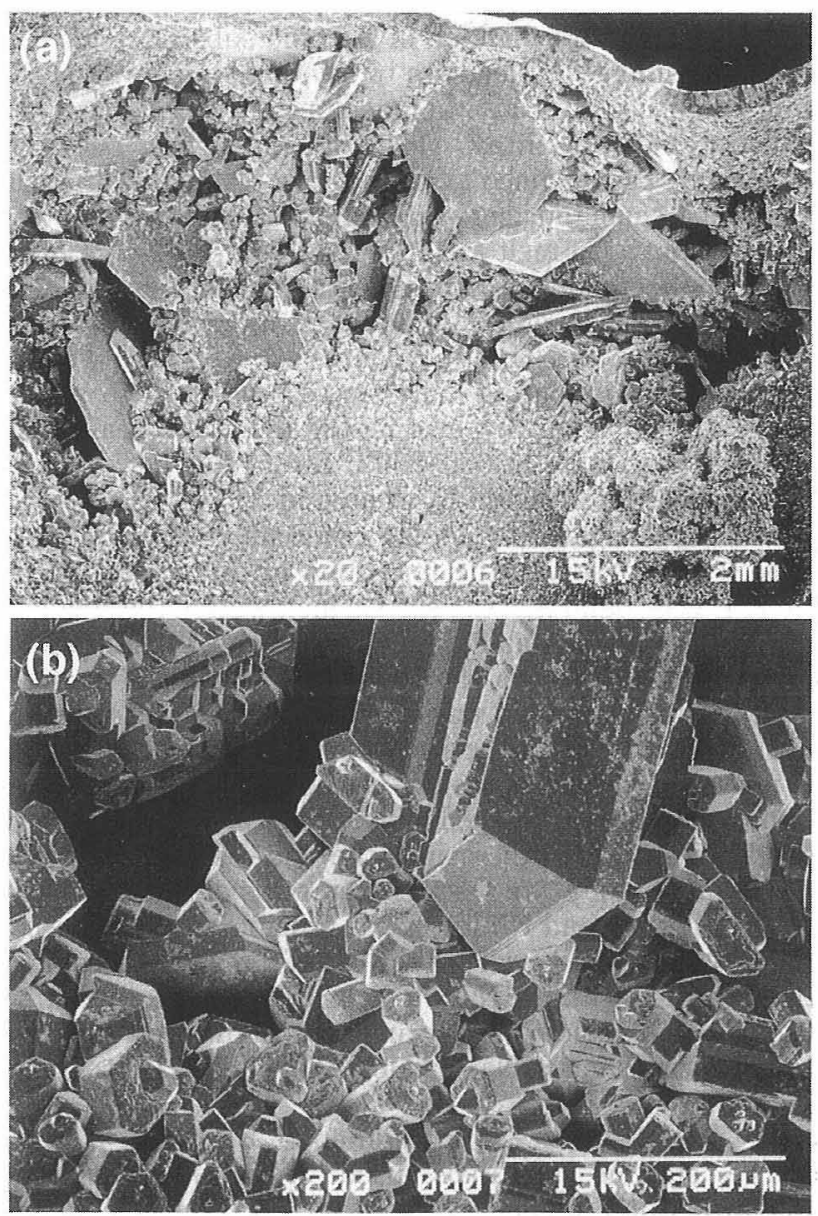

Fig. 4. Scanning electron micrographs of the GaN surface layer of sample A taken from the melt-phase side at a low magnification (a) and a high magnification (b). 
studies, ${ }^{13)-15)}$ the needle crystals were $\mathrm{Ga}_{39} \mathrm{Na}_{22}$. $\mathrm{GaN}$ also precipitated on the wall and bottom of the BN crucible.

Figure 3 shows a photograph of the GaN layer at the surface of the sample. This picture was taken from the inside (melt-phase side) after the removal of the Na metal and needle crystals by washing with ethanol. Hexagonal platelet single crystals of $1-2 \mathrm{~mm}$ were grown in and from the layer. The crystals were translucent and pale brown. As shown in the scanning electron micrographs of this side (Fig. 4), columnar crystals of $10 \mu \mathrm{m}$ precipitated among the large platelet crystals.

Figure 5 shows scanning electron micrographs of the GaN surface layer observed from the $\mathrm{N}_{2}$ gas-phase side. The crystals with various sizes were patched together. The largest one was approximately $0.3 \mathrm{~mm}$ in diameter. Hexagonal pits were observed on the hexagonal crystal faces. This may have a reverse relation to the hexagonal hillocks observed previously on the Ga side of the platelet single crystals grown in the stainless-steel tube. ${ }^{17)}$ The planes with the hexagonal pits might correspond to the $\mathrm{N}$ side of the GaN crystals. Many edges and steps were observed on the other planes of the GaN crystals.

Scanning electron micrographs of the GaN precipitated on the bottom of the BN crucible are shown in Fig. 6. The precipitates were removed from the $\mathrm{BN}$ crucible with a razor. No reaction was observed between the $\mathrm{BN}$ crucible and GaN. The XRD pattern of the powdered sample from the crucible bottom was consistent with the presence of two phases, BN and GaN. As shown in Fig. 6(a), granules of 20-30 $\mathrm{mm}$ in diameter were observed on the precipitate at a
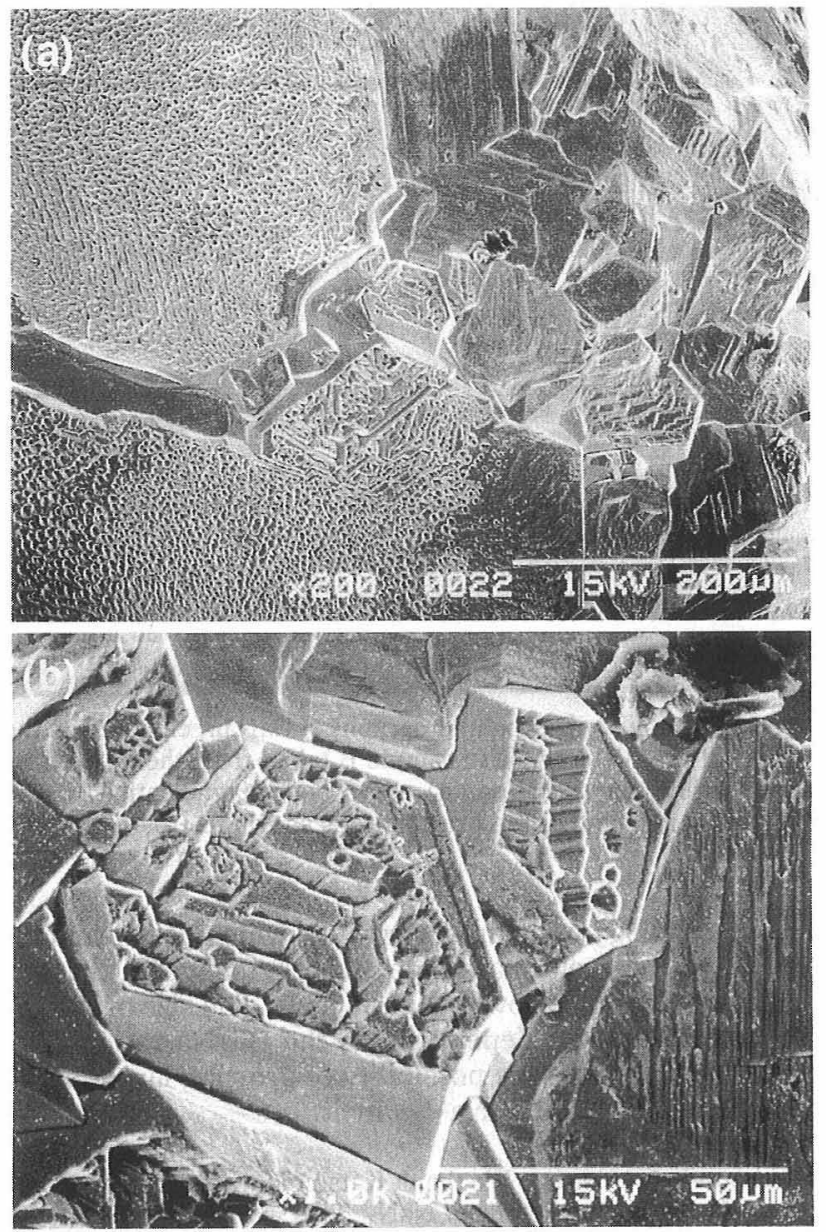

Fig. 5. Scanning electron micrographs of the GaN surface layer of sample A taken from the gas-phase side at a low magnification (a) and a high magnification (b). low magnification. Figure 6(b) revealed that these were composed of columnar crystals of about $5 \mu \mathrm{m}$ in length, growing radially outwards from the center. On the cross-sectional view (Fig. 6(c)), the grain size of the crystals increased from outside to inside and columnar crystals of 10-20 $\mu \mathrm{m}$ grew toward the melt.

Figure 7 (a) shows the XRD pattern of the powdered sample of the surface layer. All diffraction peaks were indexed as hexagonal $\mathrm{Pb}_{3} m c$ with lattice parameters $a=0.3188$ (1) and $c=0.5186(1) \mathrm{nm}$, which were consistent with the reported values. ${ }^{17)-19)}$ The XRD patterns of the precipitate fragment taken from the bottom side (Fig. 7 (b)) and from the melt side (c) exhibited a preferred orientation of (001). This corresponded to the crystal growth of columnar $\mathrm{GaN}$
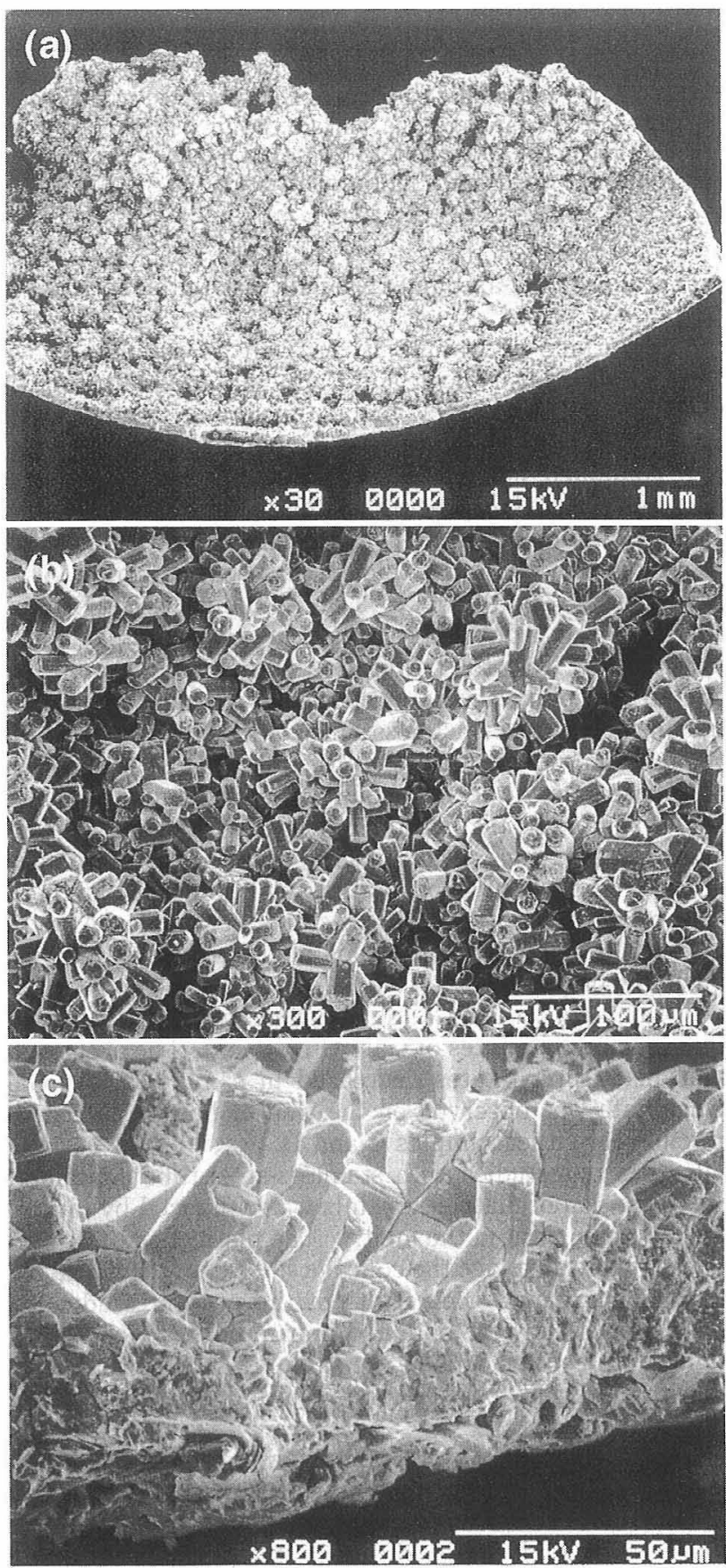

Fig. 6. Scanning electron micrographs of $\mathrm{GaN}$ precipitated on the bottom of BN crucible for sample A taken from the melt-phase side at a low magnification (a) and a high magnification (b). A crosssectional view of the precipitate is shown in (c). 


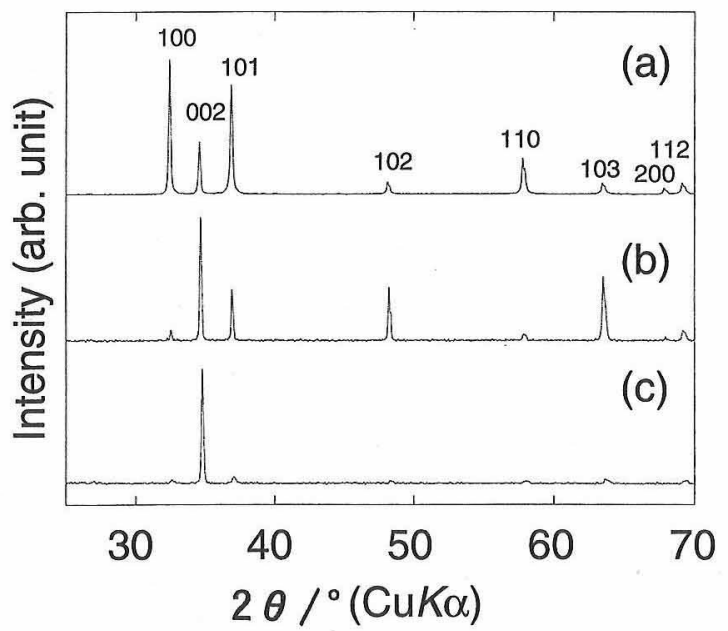

Fig. 7. X-ray diffraction patterns of $\mathrm{GaN}$ obtained in sample A : the powdered sample of the surface layer (a), the fragment precipitated on the bottom of the BN crucible taken from the meltphase side (b) and from the BN crucible side (c).

grains along the $c$-axis and perpendicular to the bottom surface.

The surface of sample $B$, as well as sample A, was covered with a GaN layer and Na metal oozed out from the inside (Fig. 2(b)). Na metal, including many needle crystals of the Na-Ga intermetallic compounds $\left(\mathrm{Ga}_{39} \mathrm{Na}_{22}\right)$, was contained inside. Figure 8 shows scanning electron micrographs of $\mathrm{GaN}$ precipitated on the bottom of the crucible for sample B. The thickness of the precipitates was about $200 \mu \mathrm{m}$, two times thicker than that in sample A. As shown in Figs. 8(b) and (c), GaN columnar crystals, about $50 \mu \mathrm{m}$ on one side of the hexagonal edge and $100 \mu \mathrm{m}$ in length, grew from the bottom to the melt side. Similar columnar precipitates were observed on the melt side of the surface layer. The thickness of the surface layer was 300$400 \mu \mathrm{m}$, and no large platelet crystals were observed. The gas-phase side of the surface layer had a texture similar to that of sample A. It consisted of crystals of 50-200 $\mu \mathrm{m}$, and many pits and edges were observed on the crystal planes.

The fragments of GaN obtained at the surface and on the bottom and wall of the BN crucibles in samples A and B were black. However, the color of the powdered samples was light brown.

In sample $\mathrm{C}$, a Na-Ga alloy surface was partly covered with black precipitates of GaN (Fig. 2(c)). The area of the GaN black precipitates decreased in sample D. No GaN precipitate was observed on the wall or bottom of the $\mathrm{BN}$ crucible for either samples C and D.

In previous studies with stainless-steel tube containers, the formation of platelet crystals was enhanced by increasing the Na content in the melt. ${ }^{15}$ ) The platelet crystals grew on the tube wall above the concave surface of the melt. This result is similar to the results of the present study. The platelet crystals were obtained in sample A which had the highest Na content among the samples. The crystals grew near the interface between the melt and gas phases.

\section{Conclusion}

GaN single crystals were synthesized using a Na-Ga melt in a $\mathrm{BN}$ crucible at $650^{\circ} \mathrm{C}$. Because of the low wettablity of $\mathrm{Na}-\mathrm{Ga}$ melt against $\mathrm{BN}$, the melt stayed at the bottom of the $\mathrm{BN}$ crucible. We observed the morphology of GaN crystals not only near the interface between the melt and gas phases but also at the bottom of the crucible where the crystals were completely covered with the Na-Ga melt.
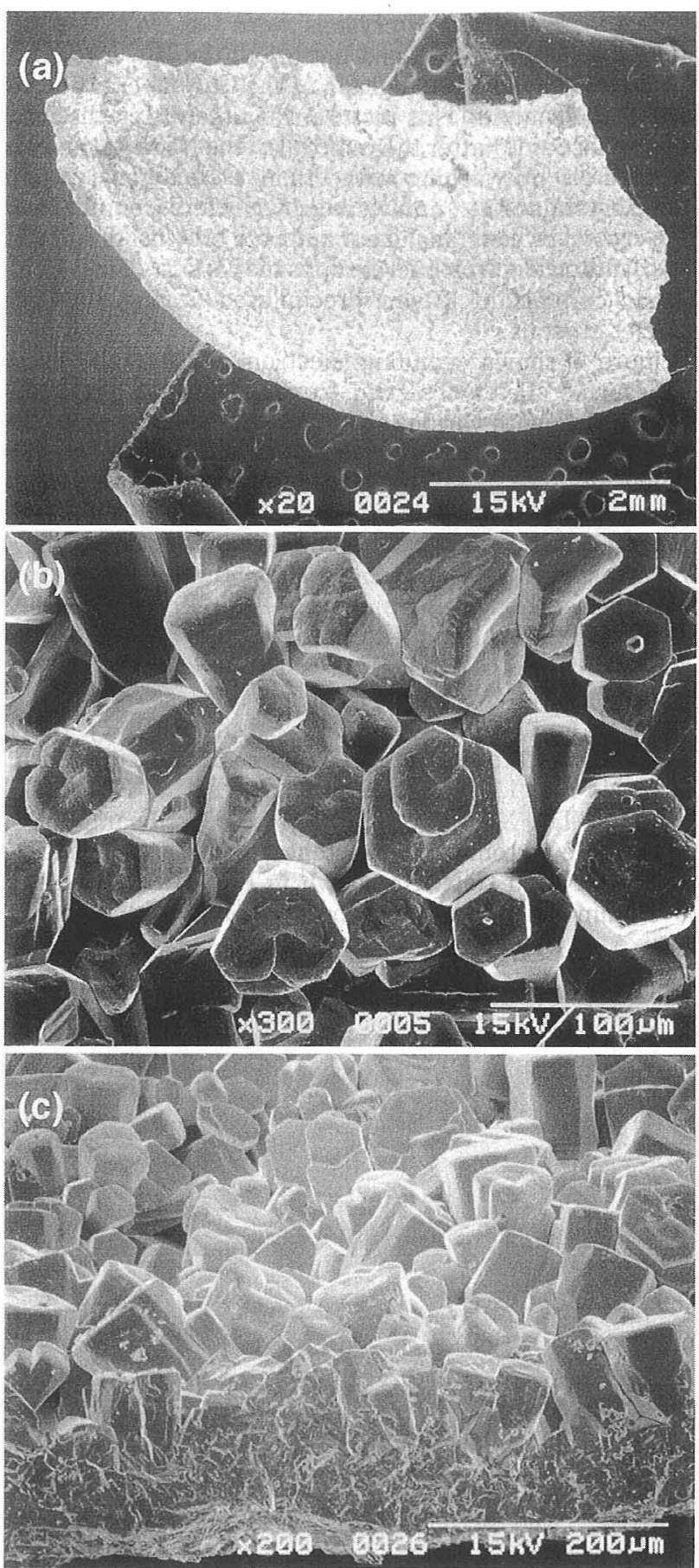

Fig. 8. Scanning electron micrographs of $\mathrm{GaN}$ precipitated on the bottom of the BN crucible in sample B taken from the melt-phase side at a low magnification (a) and a high magnification (b). A cross-sectional view of the precipitate is shown in (c).

The morphology of columnar crystals which grew from the bottom to the melt-phase side strongly suggests that the GaN crystals could grow in Na-Ga melt. The size of the columnar crystals was dependent on the $\mathrm{Ga} / \mathrm{Na}$ ratios. This result demonstrates the possibility of growing larger single crystals of $\mathrm{GaN}$ from a Na-Ga melt.

Acknowledgements We thank Katsumi Sawane of Toyo Kasei Kogyo Co., Ltd. for the gift of $\mathrm{NaN}_{3}$. This work was supported in part by the Ministry of Education, Science, Sports and Culture through a Grant-in-Aid for Scientific Research (No. 09555274), and by the NEDO International Joint Research Program. 


\section{References}

1) J. W. Orton and C. T. Foxon, Rep. Prog. Phys., 61, 1-75 (1998).

2) F. A. Ponce and D. P. Bour, Nature, 386, 351-59 (1997).

3) H. Morkoç and S. N. Mommand, Science, 267, 51-55 (1995).

4) S. Porowski, J. Cryst. Growth, 189/190, 153-58 (1998).

5) R. B. Zetterstrom, J. Mater. Sci., 5, 1102-04 (1970).

6) T. L. Chu, K. Ito, R. K. Smeltzer and S. S. C. Chu, J. Electrochem. Soc., 121, 159-62 (1974).

7) R. A. Logan and C. D. Thurmond, J. Electrochem. Soc., 119, 1727-35 (1972).

8) E. Ejder, J. Cryst. Growth, 22, 44-46 (1974).

9) T. Ogino and M. Aoki, Oyo Buturi, 48, 269-72 (1979).

10) D. Elwell, R. S. Feugleson, M. M. Simkins and W. A. Tiller, J. Cryst. Growth, 66, 45-54 (1984).

11) S. Kurai, Y. Naoi, T. Abe, S. Ohmi and S. Sasaki, Jpn. J. Appl. Phys., 35, L77-79 (1996).

12) S. Kurai, K. Nishino and S. Sakai, Jpn. J. Appl. Phys., 36,
L184-86 (1997).

13) H. Yamane, M. Shimada, S. J. Clarke and F. J. DiSalvo, Chem. Mater., 9, 413-16 (1997).

14) H. Yamane, M. Shimada, T. Sekiguchi and F. J. DiSalvo, J. Cryst. Growth, 186, 8-12 (1998).

15) H. Yamane, D. Kinno, M. Shimada, T. Sekiguchi and F. J. DiSalvo, submitted to J. Mater. Sci.

16) A. D. Pelton and S. Larose, "Binary Alloy Phase Diagrams," Ed. by T. B. Massalski, H. Okamoto, P. R. Subramanian and L. Kacprzak, ASM International First Printing, OH (1990) pp. 1827-28.

17) H. Yamane, M. Shimada, T. Endo and F. J. DiSalvo, Jpn. J. Appl. Phys., 37, 3436-40 (1998).

18) H. Maruska and J. J. Tietjen, Appl. Phys. Lett., 15, 327-29 (1969).

19) M. Lesaczynski, H. Teisseyre, T. Suski, I. Grezegory, M. Bockowski, J. Jun, K. Pakula, J. M. Baranowski, C. T. Foxon and T. S. Cheng, Appl. Phys. Lett., 69, 73-75 (1996). 